Theme Issue:: Unveiling Contemporary Urban Transformations in the Arabian Peninsula Dynamics of Global Flows, Multiple Modernities, and PeopleEnvironment Interactions

Guest Editor: Professor Ashraf M. Salama and Dr. Florian Wiedmann, Department of Architecture and Urban Planning, College of Engineering, Qatar University, Doha, Qatar E-mail: asalama@gmail.com
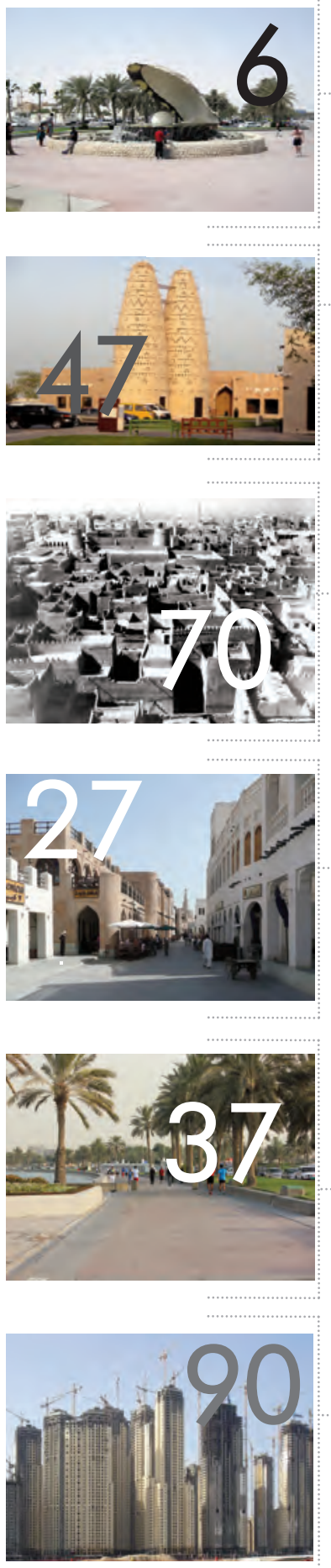

EDITORIAL: Ashraf M. Salama and Florian Wiedmann

MANUFACTURING THE IMAGE OF DOHA: FROM THE PUBLIC FACE OF ARCHITECTURE TO THE PRINTED MEDIA Ashraf M. Salama

THE SPATIAL DEVELOPMENT POTENTIALS OF BUSINESS 16 DISTRICTS IN DOHA: THE CASE OF THE WEST BAY Velina Mirincheva, Florian Wiedmann and Ashraf M. Salama

URBAN RECONFIGURATION AND REVITALISATION: PUBLIC MEGA PROJECTS IN DOHA'S HISTORIC CENTRE Florian Wiedmann, Velina Mirincheva and Ashraf M. Salama

UNDERSTANDING INHABITANTS' SPATIAL EXPERIENCE OF THE CITY OF DOHA THROUGH COGNITIVE MAPPING Ashraf M. Salama, Ahood Al-Maimani, and Fatma Khalfani EXPERIENTIAL ASSESSMENT OF URBAN OPEN SPACES IN DOHA Ashraf M. Salama, Fatma Khalfani, and Ahood Al-Maimani FROM SOUQS TO EMPORIUMS: 58 THE URBAN TRANSFORMATION OF ABU DHABI Yasser Elsheshtawy

URBAN TRANSFORMATION IN THE CITY OF RIYADH: 70 A STUDY OF PLURAL URBAN IDENTITY Mashary A. Al Naim

TRACING THE EVOLUTION OF URBANISM IN KUWAIT 80

Yasser Mahgoub

THE VERTICALIZATION OF MANAMA'S URBAN PERIPHERY

90 Florian Wiedmann

IMPORTING EXCEPTIONAL BUILDINGS:TRANSFORMING URBAN 101 ARABIAN PENINSULA INTO SKYSCRAPER CITIES Kheir Al-Kodmany and Mir M. Ali

NEXT ISSUE: VOL. 39.NO.1 2014: OPEN ISSUE Covering: Climate-Adaptive Behaviours, Collaborative Design, Courtyard House, Feng Shui, Deconstruction, Housing Co-operatives, Urban Planning, Low Carbon Cities Frameworks, Loft Conversions, Sustainable Urbanism.

Editor: Nicholas Wilkinson RIBA, Eastern Mediterranean University, North Cyprus. DPU Associate, University College London, UK. E-Mail: nicholaz.wilkinson@emu.edu.tr

Open House International has been selected for coverage by EBSCO Publishing, the ELSEVIER Bibliographic Database Scopus and all products of THOMSON ISI index bases, SSCI, A\&HCI,CC/S\&BS and CC/A\&H The journal is also listed on the following Architectural index lists: RIBA, ARCLIB, AVERY and EKISTICS. Open House International is online for subscribers and gives limited access for non-subscribers at www.openhouse-int.com 


\section{Evolving Urbanism of Cities on the Arabian Peninsula}

Covering about three million square kilometres, the Arabian Peninsula is mainly a diverse landscape of hot humid sandy coasts, arid desert, sparse scrubland, stone-strewn plains, and lush oases, as well as rocky and sometimes fertile mountain highlands and valleys. In addition to the indigenous local populace, the population is composed of large groups of expatriate Arabs and Asians, in addition to smaller groups of Europeans and North Americans; these expatriate groups represent a major workforce community of skilled professionals and semi-skilled or unskilled labourers from over sixty countries. The region's contemporary economy, dominated by the production of oil and natural gas has created unprecedented wealth, which in turn has led to a momentous surge in intensive infrastructural development and the construction of new environments (Wiedmann, 2012). The ensuing impact of this fast track development on the built environment, in conjunction with the continuous and seemingly frantic quest for establishing unique urban identities (Salama, 2012), is seen as a trigger for introducing this special edition of Open House International.

At the dawn of the new millennium, rulers, decision-makers, and top government officials started to demonstrate a stronger and more attentive interest in architecture, urban development projects and real estate investment; this concerted interest and attention have resulted in a new influential phase impacting on the development of architecture and urbanism in the Arabian Peninsula (Salama and Wiedmann, 2013). Cities on the Arabian Peninsula are continuously witnessing dramatic twists and turns that represent a diverse array of intents and attitudes (Salama, 2011 ). This can be explained by a series of vibrant discussions, characterised by a new unbiased openness, of the contemporary condition of architecture and urbanism in the Gulf region with its variety and plurality of perspectives and interests.

"With their varied socio-physical, socioeconomic, socio-cultural, and socio-political presence, cities are always been highly differentiated spaces expressive of heterogeneity, diversity of activities, entertainment, excitement, and pleasure. They have been (and still are) melting pots for the formulation of and experimentation with new philosophies and religious and social practices. Cities produce, reproduce, represent, and convey much of what counts today as culture, knowledge, and politics" (Salama and Wiedmann, 2013). Evidently this statement manifests the significance of studying cities. While this edition addresses several cities on the Arabian Peninsula, emphasis is placed on key transformational aspects relevant to five important cities that include Doha, Abu-Dhabi, Riyadh, Kuwait, and Manama.

Building on the efforts currently undertaken by the guest editors of this issue as part of a research project funded by Qatar National Research Fund (QNRF) under the National Priorities Research Program (NPRP), five papers focus on the city of Doha as one of the important rapidly growing cities on the Peninsula (Wiedmann, Salama, Thierstein, 2012). Each of the five papers discusses specific issues related to architecture and urbanism of the city. In the first paper, Salama explores image-making efforts in the city and introduces a multi-layered critical discussion based on analyses of the visual attributes of architecture and the way in which the city is portrayed in the printed media to materialize a hub vision. Mirincheva, Wiedmann, and Salama explore, in the second paper, the spatial development potentials of the West Bay as a vital rising business district in the city of Doha. In the third paper, Wiedmann, Mirincheva, and Salama elaborate on how public initiatives are altering existing urban structures and examine the extent to which the spatial reconfiguration of the historic core of the city contributes to major revitalisation objectives. In papers four and five, Salama, Khalfani, and Al Maimani investigate key dynamics of the inhabitants in relation to the physical environment of the city. Utilizing social science research techniques including cognitive and behavioural mapping, they offer an assessment of key urban nodes relevant to the way in which inhabitants experience the city and its urban spaces.

In paper six, Elsheshtawy presents a contextualization of Abu Dhabi's urban development while identifying and examining the factors that influenced its urban growth. He offers a case study of the Central Market- also known as Abu Dhabi's World Trade Center, as an important urban intervention project. Al Naim, in paper seven, offers a brief investigation of urban transformation of Riyadh from the beginning of the twentieth century until the present day with the aim of capturing the way in which inhabitants have perceived surrounding urban environments and, in turn, the resulting impact on urban planning activities. In paper eight, Mahgoub traces the evolution of urbanism in the city of Kuwait and the associated forces that instigated various urban shifts. Wiedmann, in paper nine, explores the city of Manama and how its urban periphery has witnessed dramatic transformation, namely verticalization. In essence, he examines the evolution of urban planning that resulted in the construction of high-rise buildings on the city's urban periphery by analysing urban devel- 
opment processes of key districts. The ending paper of this edition is introduced by Al Kodmany and Ali on how contemporary cities on the peninsula are being transformed by examining the role of skyscrapers in supporting place identity and how cities on the peninsula keep importing urban giants and exceptional buildings.

The ten papers presented in this special edition address critical issues and the challenges cities on the Arabian Peninsula are facing to shape a better urban future. These include the impact and characteristics of the contemporary global condition and how it is currently shaping the urban environment of those cities, how architectural and urban identities are constructed through allegorical representations that speak to the past and aspire to the future by either rooting interventions into the real or the imagined past or by yielding to the tidal wave of globalization, and how such a condition is influencing the perception and experience of the average citizen.

While the discussions raised in this edition are important and inter-disciplinary in nature, they do not offer blue prints or concrete panacea to current concerns or potential urban problems, as this is not the intent. The impetus here is to contribute to the advancement of knowledge in architecture and urbanism in a region that enjoys unique richness in its culture, economy, and geopolitical position while facing serious challenges due to its rapid urban growth. Indeed, the value of the papers presented in this volume lies in establishing a critical architectural and urban discourse that contributes to international discussions while unveils urban transformations of cities on the Arabian Peninsula at the first decade of the $21^{\text {st }}$ century.

\section{ACKNOWLEDGEMENT}

Partial support of this special issue is made through funds from the research project of the National Priorities Research Program, QNRF-Qatar National Research Fund (Project \# NPRP 09 - 1083 - 6 023). The guest editors would like to thank our peer reviewers of the papers included in this issue for their remarks and suggestions.

\section{REFERENCES}

SALAMA, A. M. 2011 . Identity Flows: The Arabian Peninsula, Emerging Metropolises. In Luis Fernández-Galiano (ed.), Atlas Architectures of the 21st Century - Africa and Middle East, Fundación BBVA, Madrid, 175-221,

SALAMA, A. M. 2012. Architectural Identity Demystified: Visual Voices from the Arab World, in P. Emmons, J. Lomholt, and J. S. Hendrix (eds.), The Cultural Role of Architecture: Contemporary and Historical Perspectives, 175-195, Routledge, London.

SALAMA, A. M. and WIEDMANN, F. 2013. Demystifying Doha: On Architecture and Urbanism in an Emerging City. Ashgate Publishing Ltd., Surrey.

WIEDMANN, F. 2012. Post-oil Urbanism in the Gulf: New Evolutions in Governance and the Impact on Urban Morphologies. SVH Verlag, Stuttgart.

WIEDMANN, F., SALAMA, A. M. and THIERSTEIN, A. 2012. Urban Evolution Of The City Of Doha: An Investigation Into the Impact of Economic Transformations on Urban Structures, in JFA/METU: Journal of the Faculty of Architecture, 29(2), 35-61.

Author(s):

Prof. Ashraf M. Salama

Professor of Architecture and Urbanism

Head, Department of Architecture and Urban Planning

Qatar University

Email: asalama@qu.ed.qa

\section{Dr. Florian Wiedmann}

Post-Doctoral Research Fellow

Department of Architecture and Urban Planning

Qatar University

Email:wiedmann.f@gmail.com 